\title{
Lumbar spine surgery positioning complications: a systematic review
}

\author{
Michael F. Shriver, BS, ${ }^{1,2}$ Valerie Zeer, BS, ${ }^{1,2}$ Vincent J. Alentado, BS, ${ }^{1,2}$ Thomas E. Mroz, MD, ${ }^{2,3}$ \\ Edward C. Benzel, MD, ${ }^{2,3}$ and Michael P. Steinmetz, MD2,3 \\ ${ }^{1}$ Case Western Reserve University School of Medicine; ${ }^{2}$ Center for Spine Health, and ${ }^{3}$ Department of Neurological Surgery, \\ Cleveland Clinic, Cleveland, Ohio
}

\begin{abstract}
OBJECT There are a variety of surgical positions that provide optimal exposure of the dorsal lumbar spine. These include the prone, kneeling, knee-chest, knee-elbow, and lateral decubitus positions. All are positions that facilitate exposure of the spine. Each position, however, is associated with an array of unique complications that result from excessive pressure applied to the torso or extremities. The authors reviewed clinical studies reporting complications that arose from positioning of the patient during dorsal exposures of the lumbar spine.
\end{abstract}

METHODS MEDLINE, Scopus, and Web of Science database searches were performed to find clinical studies reporting complications associated with positioning during lumbar spine surgery. For articles meeting inclusion criteria, the following information was obtained: publication year, study design, sample size, age, operative time, type of surgery, surgical position, frame or table type, complications associated with positioning, time to first observed complication, long-term outcomes, and evidence-based recommendations for complication avoidance.

RESULTS Of 3898 articles retrieved from MEDLINE, Scopus, and Web of Science, 34 met inclusion criteria. Twentyfour studies reported complications associated with use of the prone position, and 7 studies investigated complications after knee-chest positioning. Complications associated with the knee-elbow, lateral decubitus, and supine positions were each reported by a single study. Vision loss was the most commonly reported complication for both prone and kneechest positioning. Several other complications were reported, including conjunctival swelling, ischemic orbital compartment syndrome, nerve palsies, thromboembolic complications, pressure sores, lower extremity compartment syndrome, and shoulder dislocation, highlighting the assortment of possible complications following different surgical positions. For prone-position studies, there was a relationship between increased operation time and position complications. Only 3 prone-position studies reported complications following procedures of less than 120 minutes, 7 studies reported complications following mean operative times of 121-240 minutes, and 9 additional studies reported complications following mean operative times greater than 240 minutes. This relationship was not observed for knee-chest and other surgical positions.

CONCLUSIONS This work presents a systematic review of positioning-related complications following prone, kneechest, and other positions used for lumbar spine surgery. Numerous evidence-based recommendations for avoidance of these potentially severe complications associated with intraoperative positioning are discussed. This investigation may serve as a framework to educate the surgical team and decrease rates of intraoperative positioning complications. http://thejns.org/doi/abs/10.3171/2015.7.FOCUS15268

KEY WORDS lumbar spine surgery; prone; knee-chest; positioning complications; systematic review

$\mathrm{E}$ XPOSURE of the lumbar spine is achieved through a variety of intraoperative surgical positions. ${ }^{4}$ The prone, kneeling, knee-chest, knee-elbow, and lateral decubitus positions represent plausible positions that allow for exposure of the lumbar spine. However, each of these positions has an array of unique complications. ${ }^{4,6,11,14,28,30}$
These complications result from excessive pressure applied to ventral or lateral structures, causing potentially significant postoperative morbidity. 4, , ,11,14,15,22,31,33,39,47 While certain complications are transient, some result in permanent deficit and severe disability in patients undergoing lumbar spine surgery. ${ }^{7,11,15,21,23,28,32}$ Thus, surgeons must be

ABBREVIATIONS ASIS = anterior superior iliac spine; DVT = deep vein thrombosis; PE = pulmonary embolism; PRISMA = Preferred Reporting Items for Systematic Reviews and Meta-Analyses.

SUBMITTED May 29, 2015. ACCEPTED July 9, 2015.

INCLUDE WHEN CITING DOI: 10.3171/2015.7.FOCUS15268. 
mindful of intraoperative patient positioning to relieve potentially harmful pressure upon susceptible structures. ${ }^{4}$

Complications related to positioning during lumbar spine surgery are typically analyzed from an institutional perspective. ${ }^{14,26,29,46} \mathrm{~A}$ systematic review of complications following the numerous positioning options for lumbar spine surgery has not been previously performed. The goal of the present study is to educate the surgical team on avoiding intraoperative positioning complications, thereby improving patient outcomes. We sought to identify reported complications following different intraoperative positions for lumbar spine surgery and offer evidence-based recommendations for prevention of these potentially serious complications.

\section{Methods \\ Identification of Studies}

A systematic review of the literature was conducted following Preferred Reporting Items for Systematic Reviews and Meta-Analyses (PRISMA) criteria. ${ }^{27}$ We conducted MEDLINE, Scopus, and Web of Science database searches with the following search algorithm: (("positioning" or "position") and "complications") or (("prone" or "prone position") and "complications") or (("knee-chest" or "kneeling") and "complications") or (("lateral" or "lateral decubitus") and "complications") and ("lumbar" and ("spine" or "surgery")). The search returned 3898 citations. The search period ended April 24, 2015.

\section{Inclusion and Exclusion Criteria}

Clinical studies performing any type of lumbar spine surgery, regardless of indication, were included in the study. To create a more homogeneous patient cohort, studies involving procedures across both the thoracic and lumbar spine were excluded. We imposed no restrictions on publication status. Animal, in vitro, biomechanical, and non-English language studies were excluded. Because of the limited amount of data, we included prospective and retrospective studies reporting complications associated with positioning during lumbar spine surgery.

\section{Data Collection}

Two reviewers (M.F.S. and V.Z.) independently conducted data extraction from the 34 included articles. The extracted data sets were compared to confirm accuracy. The level of evidence of the included articles was assessed using the Oxford Centre for Evidence Based Medicine Level of Evidence 2 classification system (http://www. cebm.net/ocebm-levels-of-evidence/). Bias risk assessment was not performed for the individual studies in our review because most studies were retrospective case reports expressing strong inherent bias. The included studies are summarized in Tables 1, 2, and 3. From the eligible articles we obtained the following information: publication year, study design, sample size, sex, age, operative time, type of surgery, surgical position used, frame or table type, complications associated with positioning, time to first observed complication, long-term outcomes, and evidence-based recommendations for avoidance.

\section{Results \\ Study Selection}

Two reviewers (M.F.S. and V.Z.) evaluated the initial 3898 retrieved citations. After removing 2101 duplicates, the titles and abstracts of 1797 publications were screened. ${ }^{27}$ Studies that did not pertain to lumbar spine surgery and/or complications associated with intraoperative positioning were excluded. After excluding 1642 citations that did not meet the inclusion criteria, the full text of the remaining 155 articles was assessed. This resulted in 34 eligible articles being included in the final analysis (Fig. 1).

\section{Study Characteristics}

Of the 34 included studies in this review, 27 were case reports. The remaining studies included 2 randomized controlled trials and 1 prospective and 4 retrospective cohort studies. The year of publication ranged from 1973 to 2014. Study size ranged from 1 to 1111 patients. Twentyfour studies performed surgery in the prone position (Table 1), and 7 studies investigated complications following lumbar spine surgery in the knee-chest position (Table 2). ${ }^{1,2,5-7,9-11,13,15,18,19,21-26,28,29,32-34,36,37,39,40,42,46-48}$ Complications related to the knee-elbow, lateral decubitus, and supine positions were each reported by a single study (Table 3)..$^{14,30,31}$

\section{Prone-Position Studies}

Vision loss was the most commonly reported complication, with 11 case reports describing postoperative-onset vision loss. Three studies reported conjunctival swelling (chemosis) (Tables 1 and 4). A number of complications were reported by 2 studies in our review (i.e., cerebral infarction, ischemic orbital compartment syndrome, nerve palsies, and thromboembolic complications), showing the diversity of possible complications following prone positioning.

There was a positive correlation between increased operative time and the number of studies reporting complications related to the surgical position of the patient. Only 3 studies reported complications following procedures of less than 120 minutes, 7 studies reported complications following mean operative times of 121-240 minutes, and 9 additional studies reported complications following mean operative times of more than 240 minutes (Table 5). Vision loss and conjunctival swelling were reported across all operative time groups, whereas abdominal compartment syndrome, small bowel obstruction, acute angleclosure glaucoma, and nerve palsy were only witnessed in studies with mean operative durations of more than 240 minutes. The shortest operative time resulting in a postoperative positioning complication was 50 minutes, reported by Yilmaz and Kalemci, ${ }^{46}$ who described the development, in a single patient, of unilateral cortical blindness and concordant occipital infarction 2 hours after surgery. ${ }^{46}$

\section{Knee-Chest Studies}

There were significantly fewer studies reporting use of the knee-chest position relative to the prone position in this review (7 vs 24, respectively) (Tables 1 and 2). Acute renal failure, rhabdomyolysis, insecure endotracheal intu- 
TABLE 1. Prone-position studies identified by systematic review

\begin{tabular}{|c|c|c|c|c|c|c|}
\hline Authors \& Year & $\begin{array}{l}\text { Study } \\
\text { Design }\end{array}$ & Position & Sample Size & $\begin{array}{l}\text { Mean Age } \\
\quad(y r s)\end{array}$ & $\begin{array}{l}\text { Mean Op Time } \\
\text { in Mins }\end{array}$ & Complications Presented \\
\hline Pirris \& Nottmeier, 2013 & Case report & Prone & 1 & 65 & - & Diplopia, CN VI palsy, pneumocephalus \\
\hline Yilmaz \& Kalemci, 2013 & Case report & Prone & 1 & 53 & 50 & Vision loss, cerebral infarction (unilat occipital) \\
\hline Dahab et al., 2012 & Case report & Prone & 1 & 47 & - & Lower-extremity compartment syndrome \\
\hline Goni et al., 2012 & Case report & Prone & 1 & 38 & 105 & Vision loss, cerebral infarction (bilat occipital) \\
\hline Minami et al., 2012 & Case report & Prone & 1 & 76 & 216 & CVC-related venous thrombosis \\
\hline Chae et al., 2011 & Case report & Prone & 1 & 22 & 210 & $\begin{array}{l}\text { Bite injury, cyanotic \& edematous protruding } \\
\text { tongue }\end{array}$ \\
\hline Shih et al., 2011 & Case report & Prone & 4 & 62 & 374 & $\begin{array}{l}\text { Abdominal compartment syndrome, small-bowel } \\
\text { obstruction }\end{array}$ \\
\hline Zimmerer et al., 2011 & Case report & Prone & 1 & 73 & - & Vision loss \\
\hline Singer \& Salim, 2010 & Case report & Prone & 1 & 68 & $>300$ & Acute angle-closure glaucoma \\
\hline Cho \& Lee, 2008 & Case report & Prone & 1 & 51 & 270 & $\begin{array}{l}\text { Entrapment neuropathy of lat femoral cutaneous } \\
\text { nerve }\end{array}$ \\
\hline $\begin{array}{l}\text { Mohammadi \& Hosseini, } \\
2008\end{array}$ & RCT & Prone & HN 70, HD 70 & HN 58, HD 53 & HN 101, HD 121 & Chemosis \\
\hline Reddy et al., 2008 & Case report & Prone & 1 & 55 & 270 & Vision loss \\
\hline Yu et al., 2008 & Case report & Prone & 1 & 68 & 240 & $\begin{array}{l}\text { Vision loss, ischemic orbital compartment syn- } \\
\text { drome }\end{array}$ \\
\hline Jeon et al., 2007 & RCT & Prone & HN 54, HD 54 & HN 54, HD 55 & HN 178, HN 197 & Chemosis \\
\hline Corso et al., 2006 & Case report & Prone & 1 & 58 & 330 & Vision loss, chemosis \\
\hline Leibovitch et al., 2006 & Case report & Prone & 1 & 80 & 480 & $\begin{array}{l}\text { Vision loss, ischemic orbital compartment syn- } \\
\text { drome }\end{array}$ \\
\hline Mofredj et al., 2006 & Case report & Prone & 1 & 43 & 160 & Acute bowel ischemia \\
\hline Chalam \& Shah, 2005 & Case report & Prone & 1 & 55 & 690 & Vision loss \\
\hline Ali et al., 2003 & Case report & Prone & 1 & 57 & - & $\begin{array}{l}\text { Shoulder dislocation, ischemic limb due to arte- } \\
\text { rial compression }\end{array}$ \\
\hline Suzuki et al., 2001 & Case report & Prone & 1 & 73 & - & Vision loss \\
\hline Brandt et al., 1998 & Case report & Prone & 1 & 56 & - & Fat embolism \\
\hline Dilger et al., 1998 & Case report & Prone & 1 & 44 & 720 & Vision loss \\
\hline Lee et al., 1998 & PCS & Prone & 20 & 54 & 160 & Pressure sores \\
\hline Katz et al., 1994 & Case report & Prone & 4 & 54 & $480-540$ & Vision loss \\
\hline
\end{tabular}

$\mathrm{CN}=$ cranial nerve $\mathrm{CVC}=$ central venous catheter; $\mathrm{HD}=$ head down; $\mathrm{HN}=$ head neutral; $\mathrm{PCS}=$ prospective cohort study; $\mathrm{RCT}=$ randomized controlled trial; $-=$ no data.

TABLE 2. Knee-chest position studies identified in this systematic review

\begin{tabular}{|c|c|c|c|c|c|c|}
\hline Authors \& Year & $\begin{array}{l}\text { Study } \\
\text { Design }\end{array}$ & Position & $\begin{array}{l}\text { Sample } \\
\text { Size }\end{array}$ & $\begin{array}{l}\text { Mean Age } \\
\quad(y r s)\end{array}$ & $\begin{array}{l}\text { Mean Op Time } \\
\text { in Mins }\end{array}$ & Complications Presented \\
\hline Quraishi et al., 2012 & Case report & Knee-chest & 1 & 44 & 600 & Vision loss, CN VI palsy \\
\hline Rudolph et al., 2011 & Case report & Knee-chest & 1 & 65 & 240 & $\begin{array}{l}\text { Gluteal compartment syndrome, rhabdomyolysis, renal } \\
\text { failure }\end{array}$ \\
\hline Nicol et al., 2009 & RCS & Knee-chest & 1111 & - & $49,{ }^{*} 128 \dagger$ & Thromboembolic events \\
\hline Moriano-Béjar et al., 2008 & Case report & Knee-chest & 1 & 56 & 450 & $\begin{array}{l}\text { Lower-extremity compartment syndrome, rhabdomyo- } \\
\text { lysis, renal failure }\end{array}$ \\
\hline Roth et al., 2007 & Case report & Knee-chest & 1 & 53 & - & Vision loss \\
\hline Langmayr et al., 1996 & Case report & Knee-chest & 1 & 33 & 60 & Quadriplegia, vision loss, cerebral infarction \\
\hline Alexander, 1973 & RCS & Knee-chest & 151 & - & - & $\begin{array}{l}\text { Insecure endotracheal tube, DVT, femoral vein throm- } \\
\text { bosis }\end{array}$ \\
\hline
\end{tabular}

RCS $=$ retrospective cohort study.

* Laminotomy, decompression, and disc enucleation procedures.

$\dagger$ Posterolateral spinal fusion, with or without decompression or pedicle fixation. 
TABLE 3. Miscellaneous position studies identified in this systematic review

\begin{tabular}{lllrlcl}
\hline \multicolumn{1}{c}{ Authors \& Year } & \multicolumn{1}{c}{$\begin{array}{c}\text { Study } \\
\text { Design }\end{array}$} & \multicolumn{1}{c}{ Position } & Size & (yrs) & in Mins & Complications Presented \\
\hline Osler et al., 2014 & RCS & Supine & 263 & 50 & - & Pressure sores \\
\hline Papastefanou et al., 1994 & Case report & Lat decubitus* & 2 & 55.5 & - & Femoral nerve palsy \\
\hline Eie et al., 1983 & RCS & Knee-elbow & 943 & - & - & $\begin{array}{c}\text { Upper-extremity paresis (me- } \\
\text { chanical pressure on bra- } \\
\text { chial plexus) }\end{array}$ \\
\hline
\end{tabular}

* Retroperitoneal flank approach.

bation, and quadriplegia were only reported among studies using the knee-chest position. ${ }^{1,28,21,37}$ Furthermore, vision loss was only reported by 3 studies (Table 4)..$^{21,33,36}$ There was no correlation found between increased opera- tive time and the number of studies reporting complications, but this may have been due to the limited number of studies reporting complications related to this operative approach. Lower-extremity compartment syndrome, acute

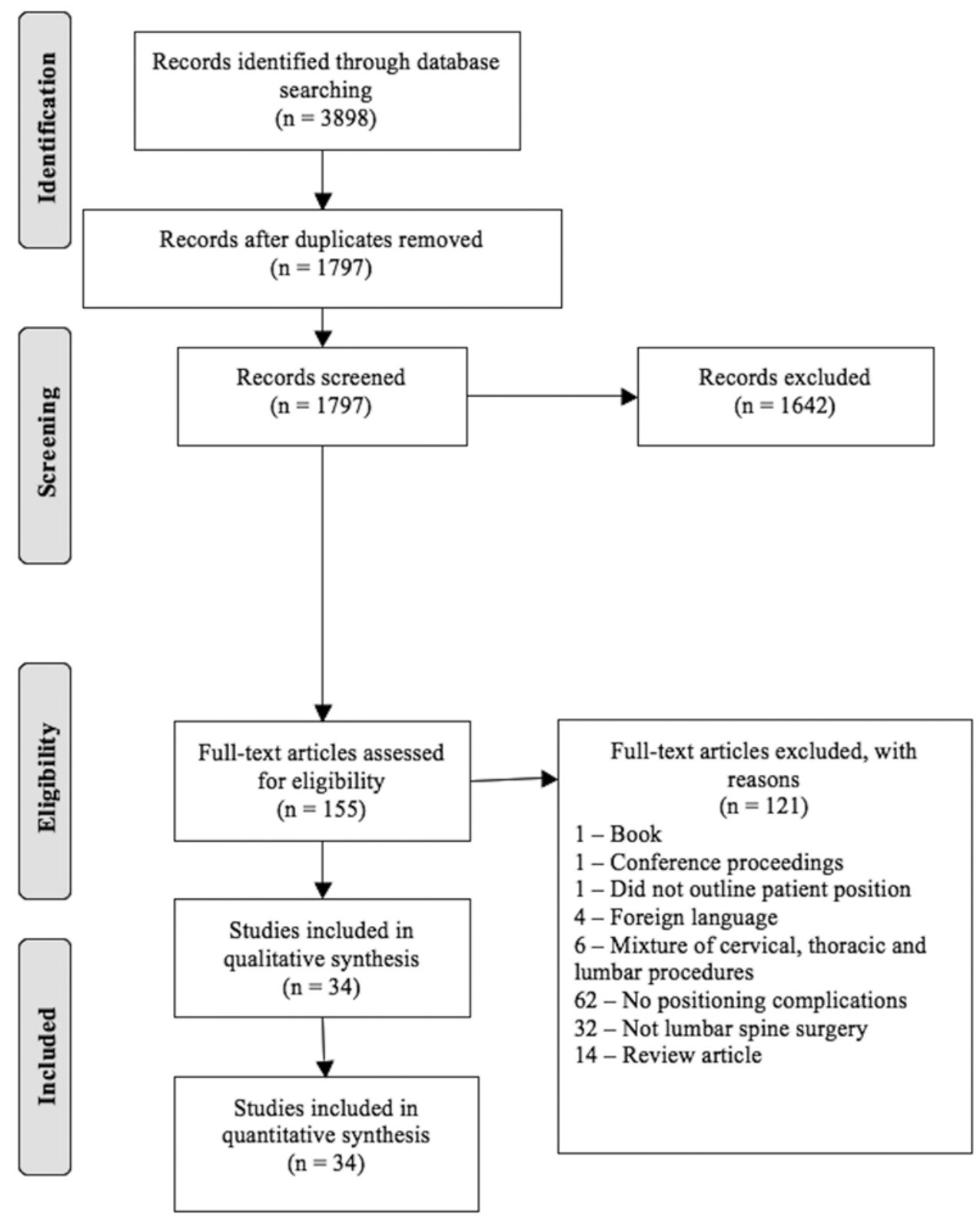

FIG. 1. PRISMA flow diagram for selection of studies based on inclusion criteria during systematic review. 
rhabdomyolysis, and acute renal failure were only reported among studies with mean operative times of more than 120 minutes, while thromboembolic complications, cerebral infarction, and vision loss were observed following shorter operation durations (Table 5). Langmayr et al. ${ }^{21}$ reported the progressive development of quadriplegia in 1 patient during the early postoperative period; it was the most significant neurological deficit following lumbar spine surgery found in our review. This occurred following a 60-minute procedure and was associated with extreme rotation or hyperextension of the head in the kneechest position. ${ }^{21}$

\section{Miscellaneous Position Studies}

Nerve palsies and pressure sores were identified in 3 studies reporting miscellaneous lumbar surgery positions (Tables 3 and 4). ${ }^{14,30,31}$ This group consisted of knee-elbow, lateral decubitus, and supine positions (Table 4). Vision loss was not reported among these studies, but the number of studies was markedly limited.

\section{Discussion}

This study represents the most comprehensive systematic literature review of positioning complications following lumbar spine surgery. We analyzed complications associated with the prone, knee-chest, and other miscellaneous intraoperative positions. Many studies within our review offered evidence-based recommendations for avoidance of these position-related complications. The most common and significant complications identified among the included studies in our review are presented below, along with prevention guidelines.

\section{Vision Loss}

Vision loss is an extremely rare complication, with reported incidences of $0.003 \%$ to $0.0008 \%$ for nonocular surgeries, and 3.09 per 10,000 for spinal fusion procedures. ${ }^{15,38,43}$ While the incidence of postoperative vision loss has not been investigated solely following lumbar spine surgery, it was the most commonly reported complication associated with intraoperative positioning during our review. Onset of vision loss can occur early during the postoperative period and may present with decreased visual acuity, lack of light perception, ophthalmoplegia, and/ or ptosis. ${ }^{47}$ These symptoms arise following ischemic optic neuropathy, central artery occlusion, ischemic orbital compartment syndrome, or occipital cerebral infarction. These findings can occur unilaterally or bilaterally. ${ }^{23,33,47,48}$ Persistent visual loss is reported in a number of cases. ${ }^{15,36,48}$ Leibovitch et al. ${ }^{23}$ reported a persistent deficit through 4 months of follow-up, with no improvement in light perception, ptosis, or ophthalmoplegia. Conversely, rapid recovery of vision within 48 hours of vision loss has been reported. ${ }^{33}$ Although the possibility exists for recovery, it is not always complete or symmetric. Chalam et al. ${ }^{7}$ reported the partial resolution of bilateral visual loss, with 1 eye exhibiting detection of hand motion and the other revealing persistent loss of light perception at 1-year follow-up.

Prevention of postoperative vision loss is critical. The pathogenesis of this significant deficit is thought to arise from venous flow obstruction caused by applied exter-
TABLE 4. Number of included studies reporting each position-associated complication

\begin{tabular}{|c|c|}
\hline Complication & No. of Studies Reporting \\
\hline Total no. prone-position studies & 24 \\
\hline Vision loss & 11 \\
\hline Conjunctival swelling & 3 \\
\hline Cerebral infarction & 2 \\
\hline Ischemic orbital compartment syndrome & 2 \\
\hline Nerve palsies & 2 \\
\hline Thromboembolic complications & 2 \\
\hline Abdominal compartment syndrome & 1 \\
\hline Acute angle-closure glaucoma & 1 \\
\hline Acute bowel ischemia & 1 \\
\hline Bite injury & 1 \\
\hline Diplopia & 1 \\
\hline Ischemic limb due to arterial compression & 1 \\
\hline Lower-extremity compartment syndrome & 1 \\
\hline Pneumocephalus & 1 \\
\hline Pressure sores & 1 \\
\hline Shoulder dislocation & 1 \\
\hline Small bowel obstruction & 1 \\
\hline Total no. of knee-chest studies & 7 \\
\hline Vision loss & 3 \\
\hline Acute renal failure & 2 \\
\hline Acute rhabdomyolysis & 2 \\
\hline Lower-extremity compartment syndrome & 2 \\
\hline Thromboembolic complications & 2 \\
\hline Cerebral infarction & 1 \\
\hline Insecure endotracheal tube & 1 \\
\hline Nerve palsies & 1 \\
\hline Quadriplegia & 1 \\
\hline Total no. of miscellaneous position studies & 3 \\
\hline Nerve palsies & $2^{*}$ \\
\hline Pressure sores & $1 \dagger$ \\
\hline
\end{tabular}

nal pressure during the operation, consequently resulting in increased orbital venous and intraocular pressure. ${ }^{7,45}$ Several risk factors are associated with this, including prolonged operative time, high-volume infusion, intraoperative anemia, and hypotension. When these risk factors are combined with applied ventral pressure to the head, a head-down position, or extreme rotation of the head to one side during prone positioning, they may result in loss of vision due to compromised blood flow to the optic nerve. ${ }^{8,10,33,46}$ For proper protection of the eyes, correct positioning must be confirmed at multiple time points before and during the operation to prevent improper shifting of the head. ${ }^{20}$ Quraishi et al. ${ }^{33}$ suggested that high-risk patients, including those with expected prolonged operative time and/or substantial blood loss, should be positioned so the head lies at or above the level of the heart, in a neutral forward position, and intraoperative eye swelling and pressure should be checked consistently. As well, the use 
TABLE 5. Reported complications relative to reported mean operative time among included studies

\begin{tabular}{|c|c|c|c|}
\hline $\begin{array}{l}\text { Surgical } \\
\text { Position }\end{array}$ & $\begin{array}{l}\text { Op Time } \\
\text { in Mins }\end{array}$ & $\begin{array}{l}\text { No. of } \\
\text { Stud- } \\
\text { ies }\end{array}$ & Complications Presented \\
\hline \multirow[t]{3}{*}{ Prone } & $\leq 120$ & 3 & Vision loss, conjunctival swelling, cerebral infarction \\
\hline & $121-240$ & 7 & $\begin{array}{l}\text { Vision loss, conjunctival swelling, ischemic orbital compartment syndrome, acute bowel ischemia, pressure sores, } \\
\text { bite injury, thromboembolic complications }\end{array}$ \\
\hline & $>240$ & 9 & $\begin{array}{l}\text { Vision loss, conjunctival swelling, acute angle-closure glaucoma, ischemic orbital compartment syndrome, nerve } \\
\text { palsy, abdominal compartment syndrome, small bowel obstruction }\end{array}$ \\
\hline \multirow[t]{3}{*}{ Knee-chest } & $\leq 120$ & 2 & Quadriplegia, vision loss, cerebral infarction, thromboembolic complications \\
\hline & $121-240$ & 2 & Lower-extremity compartment syndrome, rhabdomyolysis, renal failure, thromboembolic complications \\
\hline & $>240$ & 2 & Lower-extremity compartment syndrome, rhabdomyolysis, renal failure, vision loss, nerve palsy \\
\hline
\end{tabular}

of a head frame may be indicated to substantially reduce direct pressure to the eyes. ${ }^{33}$

Fewer published reports exist regarding postoperative vision loss following the knee-chest position compared with the prone position, but Roth et al. ${ }^{36}$ reported the onset of vision loss even with the use of a foam headrest and goggles covering the eyes. This emphasizes the highly variable and inconsistent onset of postoperative vision loss, even with the proper implementation and use of preventive measures. No matter the setting, immediate ophthalmological evaluation is necessary to increase the likelihood of recovery. ${ }^{10}$ This review highlights the need for future studies comparing the relative risk of various lumbar spine surgery positions on the incidence of postoperative vision loss.

\section{Acute Angle-Closure Glaucoma}

Singer and $\mathrm{Salim}^{40}$ reported the onset of acute angleclosure glaucoma in a patient complaining of persistent unilateral eye pain, nausea, and vomiting 2 days following lumbar fusion surgery. Measures of intraocular pressure identified a significant increase relative to normal mean values. To properly identify a patient's risk of developing acute angle-closure glaucoma, Singer and $\mathrm{Salim}^{40}$ recommend using the prone position test because of its superior sensitivity and specificity. An 8- $\mathrm{mm} \mathrm{Hg}$ rise in intraocular pressure over 60 minutes is considered significant. ${ }^{40}$ Furthermore, a $42-\mathrm{mm} \mathrm{Hg}$ elevation in intraocular pressure from baseline that can be solely attributed to the intraoperative prone position is possible. ${ }^{40}$ Anatomical factors, including ethnicity (Asians, Canadians, Eskimos), female sex, shorter axial length of eyes, and a thicker, anteriorly located lens, seem to substantially increase the risk of increased intraocular pressure and may contraindicate use of the prone position in some patients. ${ }^{40}$ One hour of prone positioning in these high-risk individuals may result in acute-angle glaucoma, substantially threatening the patient's vision. ${ }^{40}$ Thus, surgical positions that reduce applied pressure to the eyes may be indicated in high-risk individuals.

\section{Conjunctival Swelling}

Two randomized controlled trials by Mohammadi and Hosseini ${ }^{26}$ and Jeon et al. ${ }^{18}$ investigated rates of chemosis between head-neutral and head-down prone positions. Both studies found that patients with head-neutral po- sitioning, compared with the head-down position, had a lower incidence of chemosis. ${ }^{18,26}$ Additionally, positive fluid balance and increased operative time were correlated to increased chemosis development. ${ }^{18,26}$ These findings, along with the recommendations of Quraishi et al., ${ }^{33}$ support the necessity for the head to lie level with or above the rest of the body to avoid gravity-induced venous stasis and fluid collection. ${ }^{18}$ This can be achieved with the use of various headrests (i.e., cushion, foam headrest, horseshoe head rest, or head frame), but a head frame may be best because it avoids compression of periorbital structures, which may increase the risk of venous stasis..$^{26,33,36}$

\section{Quadriplegia}

Langmayr et al. ${ }^{21}$ reported a case of progressive quadriplegia development following surgery in the knee-chest position. This occurred in a 33-year-old male patient undergoing a 60 -minute operation..$^{21}$ Following the procedure, the patient complained of lower extremity paralysis, which then progressed to quadriplegia. ${ }^{21}$ MRI identified a hypointense lesion in the upper cervical spinal cord, which correlated to the patient's symptomatology. ${ }^{21}$ No embolic source was found and the authors believed it was caused by extreme rotation or hyperextension of the head in the knee-chest position. ${ }^{21}$ Loss of tone in the cervical musculature during surgery, resulting in increased cord compression in patients with preexisting cervical stenosis, systemic embolism, and/or primary vertebral artery embolism due to occlusion and subsequent stasis of arterial blood flow, was theorized..$^{16,17,21}$ Most likely, extreme rotation, flexion, or extension of the neck, and resultant stretching of the cervical cord produced impaired blood flow along the carotid and/or vertebral arteries. ${ }^{21}$ Therefore, while avoidance of applied pressure to ventral structures of the head is key for prevention of postoperative vision loss and periorbital swelling, extreme rotation or hyperextension of the neck must be circumvented because of potential impairment of blood flow to the spinal cord and cerebral hemispheres..$^{16,21}$ Neck and head position must be checked at multiple points by the surgeon and anesthesiologist to ensure prevention of this severe, life-threatening complication.

\section{Bite Injury}

Chae et al. ${ }^{6}$ reported the unusual intraoperative discovery of a bite injury, producing a cyanotic, edematous, protruding tongue. Rocuronium, a skeletal muscle relaxant, 
was administered for emergent decompression and reposition of the tongue, leading to restoration of the blood supply, reduction of edema, and, ultimately, resulting in no long-term tongue complications. ${ }^{6}$ The authors attributed this intraoperative injury to inadequate preoperative intraoral care and intraoperative wake-up test. ${ }^{6}$ With extensive concentration placed on securing proper ventilation, the prospect of tongue protrusion was inadvertently missed. ${ }^{6}$ When pressure is applied to the neck, there may be tongue displacement and decreased venous return, resulting in an edematous, enlarged tongue. ${ }^{6}$ However, with a neutral head position, neck pressure is reduced, minimizing the risk for intraoperative tongue displacement and swelling, thereby decreasing bite injuries. ${ }^{6}$ Bite blockers, if used, should be short and soft to prevent traumatic injury to the tongue and teeth, but should be sufficient enough to prevent significant intraoral cavity volume reduction. ${ }^{6}$

\section{Shoulder Dislocation}

Ali et al. ${ }^{2}$ reported the recurrence of shoulder dislocation in a patient undergoing lumbar spine fusion in the prone position following trauma. The patient's shoulders and elbows were abducted to $90^{\circ}$ and flexed, respectively, with both arms supported by an arm cushion and board. ${ }^{2}$ During the procedure, arterial blood pressure waveforms were lost, resulting in unilateral arm paleness, which was concerning for recurrent anterior shoulder dislocation. ${ }^{2}$ Ultimately, the patient suffered from an ischemic limb, secondary to axillary artery compression by shoulder dislocation. ${ }^{2}$ Fortunately, recognition of arterial-catheter waveform abnormalities allowed for early detection and prevention of potential compartment syndrome, rhabdomyolysis, and possible subsequent renal failure. ${ }^{2}$ Reduction of the dislocation, confirmation of restored arterial blood pressure, and additional support of the injured extremity allowed for continuation of the spine procedure without further complications. ${ }^{2}$ This study highlights the necessity of consistent monitoring of arterial waveforms to properly maintain perfusion of extremities during lumbar spine surgery, especially following trauma. ${ }^{2}$ The arm position in this study is routinely used because of improved catheter and monitor access. However, this may predispose patients to shoulder dislocation, and consequent brachial plexus injury and arterial impingement. , $^{2,14,41}$ The authors suggested an alternative position in patients with prior history or increased risk of shoulder dislocation: arms placed lateral relative to the chest, with adducted shoulders, extended elbows, and pronated forearms. ${ }^{2}$ Along with improved and less extreme positioning of extremities, continual inspection of peripheral pulses, capillary refill, skin tone, oximetry, and arterial-catheter waveforms should greatly reduce the risk of ischemic limb complications. . $, 6,12,13,28$

\section{Compartment Syndrome}

Compartment syndromes are rare but are representative of extreme complications that are possible following longterm operations lasting longer than 2 to 4 hours. ${ }^{11,28,37}$ The cause of increased compartmental pressures following surgery is not always apparent and may occur even with careful positioning and attention to areas under pressure. ${ }^{11}$ Lower-extremity compartment syndrome was reported in 3 studies in our review-Dahab et al., ${ }^{11}$ Rudolph et al., ${ }^{37}$ and Moriano-Béjar et al. ${ }^{28}$ - encompassing bilateral gluteal, anterior thigh, and anterior leg compartments. Compartment syndrome location was clearly related to areas of pressure applied during intraoperative positioning. Prone positioning used in Dahab et al. ${ }^{11}$ resulted in an anterior thigh syndrome, whereas Rudolph et al. ${ }^{37}$ and MorianoBéjar et al. ${ }^{28}$ reported gluteal and anterior leg compartment syndromes, respectively, because of applied pressure in the knee-chest position. Hip flexion in the knee-chest position may predispose patients to increased gluteal compartment pressure, reducing pelvic perfusion. ${ }^{37}$ Although positioning plays a role, the syndrome's etiology is likely related to multiple factors, including obesity, operative time, positioning, and intraoperative hypotension. ${ }^{37}$ To avoid lower-extremity compartment syndrome, Rudolph et al. ${ }^{37}$ suggested obese patients with risk factors for prolonged surgery time might benefit from being placed in the prone position, but noted that this position offers its own unique set of possible complications, such as abdominal and visceral ischemia, which are also associated with gluteal compartment syndrome. Ultimately, because of the ambiguity found between different positions and the development of compartment syndrome, it is important that surgeons do not confuse postoperative symptoms of extremity ischemia with preoperative deficits associated with the patient's lumbar pathology. ${ }^{28}$

\section{Pressure Sores}

Operations with a duration of more than 3 hours increase the risk of pressure sore development. ${ }^{22}$ Use of some frames, such as the Relton-Hall frame, produce increased pressure at specific points where the patient's body rests. ${ }^{22}$ In morbidly obese patients or any patient with increased risk of developing pressure ulcers, careful frame selection should be considered. Certain frames such as the Wilson, Andrews, Jackson, and longitudinal bolster tables accommodate proper lumbar spine exposure with reduced compression of ventral structures. ${ }^{4,12}$ Use of pillows and careful positioning of the abdomen and extremities diminish these pressure points as well., ${ }^{1,5,29}$ The risk and consequences of developing pressure sores is important. This review highlights the need for future studies comparing the relative risk of pressure sores following the use of various tables and frames.

\section{Thromboembolic Complications}

Nicol et al. ${ }^{29}$ suggested that intraoperative positioning plays a crucial role in the rate of deep vein thrombosis (DVT) and pulmonary embolism (PE) development following lumbar spine surgery. There is substantial variation in reported rates of thromboembolic complications following spine surgery, with some reports as high as $12 \%$, and some as low as $0.3 \% .^{35,44} \mathrm{Nicol}$ et al. reported a $0.27 \%$ rate of thrombotic complications, with no further reduction in patients receiving additional prophylactic measures (e.g., aspirin and compression stockings). The authors used a knee-chest position, with patients seated and the table tipped at $30^{\circ}$, producing a head-up orientation. ${ }^{29}$ This facilitated proper distribution of weight through the buttocks, knees, and upper chest, thereby reducing compression of the groin and popliteal fossa, and their respective blood vessels. ${ }^{29}$ Most studies do not correlate intraoperative posi- 
tioning with rates of thrombosis, but proper distribution of weight and avoidance of acute joint flexion may contribute to reduced DVT and PE incidence. . $^{1,24,29}$

Minami et al. ${ }^{24}$ further postulated that particular neck positions during lumbar spine surgery in the prone position might result in venous kinking. The patient in their case report was placed in a slightly flexed-neck position which, in combination with the presence of a central venous catheter in the internal jugular vein, potentially contributed to venous stasis and thrombosis. ${ }^{24} \mathrm{~A}$ head-neutral position to avoid venous kinking, and use of subclavian venous catheterization, reduces the risk of venous stasis and subsequent thrombotic events. ${ }^{24}$ Thus, patient positioning during lumbar spine surgery is intricately associated with thromboembolic complication rates, once again supporting the necessity of proper positioning and consistent checking throughout the procedure.

\section{Peripheral Nerve Palsies}

Damage to peripheral nerves and subsequent neurological deficit were reported following prone, knee-elbow, and lateral decubitus positioning., ${ }^{9,14,31}$ Cho and $\mathrm{Lee}^{9}$ reported entrapment neuropathy of the lateral femoral cutaneous nerve at the level of the anterior superior iliac spine (ASIS) following instrumented, posterior lumbar interbody fusion. Postoperatively, the patient complained of unilateral, anterior thigh paresthesia, but no muscle weakness. ${ }^{9}$ No concurrent lumbar radiculopathy was diagnosed following electrodiagnostic testing. 9 The sensory deficit was associated with placement of the pelvic bolster under the ASIS during prone-position surgical technique. ${ }^{9}$ This complication was witnessed following an operative time of 270 minutes. $^{9}$ Increased operative time is a clear risk factor during lumbar spine surgery, because of excessive pressure applied to peripheral nerve locations. Eie et al. ${ }^{14}$ reported the onset of transient right-arm paresis because of pressure applied to the brachial plexus during intraoperative knee-elbow positioning. Papastefanou et al. ${ }^{31}$ reported compressive neuropathy of the femoral nerve associated with the lateral decubitus position during anterior lumbar interbody fusion. The authors, following anatomical study, stated that immobility of the lumbar spine from a prior fusion, combined with hip extension during the procedure, resulted in constriction of the femoral nerve. ${ }^{31}$ Compressive injury resulting in postoperative neurological deficits is a potential complication following multiple positions for lumbar spine surgery. To avoid postoperative neurological deficit, surgeons must remain vigilant for excessive intraoperative pressure near key peripheral nerve locations.

\section{Limitations}

Most studies in our review were retrospective case reports, preventing us from calculating pooled complication rates. Furthermore, it is very likely that severe complications, like quadriplegia, are underreported. In addition, while stratification of complications by table and frame type would decrease heterogeneity among studies and reveal inherent differences, the primary literature is varied and does not routinely differentiate in reporting operative procedures. This review highlights the need for future studies comparing the relative risk of various lumbar spine surgery positions, tables, and frames on the incidence of postoperative complications.

\section{Conclusions}

This work presents a systematic review of positioning complications following prone, knee-chest, and other positions used for lumbar spine surgery. Heterogeneity among reporting likely reflects the real-world practice and conceptualization of complications by surgeons. Vision loss was the most commonly reported complication following both prone and knee-chest positioning. We discuss numerous evidence-based recommendations for avoidance of potentially severe complications associated with intraoperative positioning. Such an investigation should serve as a framework to provide education to the surgeon and decrease the rates of position-related complications in patients.

\section{References}

1. Alexander JP: Problems associated with the use of the kneechest position for operations on lumbar intervertebral discs. J Bone Joint Surg Br 55:279-284, 1973

2. Ali AA, Breslin DS, Hardman HD, Martin G: Unusual presentation and complication of the prone position for spinal surgery. J Clin Anesth 15:471-473, 2003

3. Anderton JM: The prone position for the surgical patient: a historical review of the principles and hazards. $\mathbf{B r} \mathbf{J}$ Anaesth 67:452-463, 1991

4. Benzel EC: Spine Surgery: Techniques, Complication Avoidance, and Management, ed 3. Philadelphia: Elsevier/ Saunders, 2012

5. Brandt SE, Zeegers WS, Ceelen TL: Fatal pulmonary fat embolism after dorsal spinal fusion. Eur Spine J 7:426-428, 1998

6. Chae YJ, Kim JY, Yoo JY, Choi YH, Park KS: Tongue bite in a patient with tracheostomy after prone position-a case report. Korean J Anesthesiol 60:365-368, 2011

7. Chalam KV, Shah VA: Severe bilateral posterior ischemic optic neuropathy as a complication of spinal surgery. Eye (Lond) 19:367-368, 2005

8. Chang SH, Miller NR: The incidence of vision loss due to perioperative ischemic optic neuropathy associated with spine surgery: the Johns Hopkins Hospital Experience. Spine (Phila Pa 1976) 30:1299-1302, 2005

9. Cho KT, Lee HJ: Prone position-related meralgia paresthetica after lumbar spinal surgery: a case report and review of the literature. J Korean Neurosurg Soc 44:392-395, 2008

10. Corso CM, Tanaka PP, Khon K: [Optic nerve ischemia after spine surgery: case report.] Rev Bras Anestesiol 56:273277, 2006 (Portuguese)

11. Dahab R, Barrett C, Pillay R, De Matas M: Anterior thigh compartment syndrome after prone positioning for lumbosacral fixation. Eur Spine J 21 (Suppl 4):S554-S556, 2012

12. Dharmavaram S, Jellish WS, Nockels RP, Shea J, Mehmood $\mathrm{R}$, Ghanayem A, et al: Effect of prone positioning systems on hemodynamic and cardiac function during lumbar spine surgery: an echocardiographic study. Spine (Phila Pa 1976) 31:1388-1394, 2006

13. Dilger JA, Tetzlaff JE, Bell GR, Kosmorsky GS, Agnor RC, O'Hara JF Jr: Ischaemic optic neuropathy after spinal fusion. Can J Anaesth 45:63-66, 1998

14. Eie N, Solgaard T, Kleppe H: The knee-elbow position in lumbar disc surgery: a review of complications. Spine (Phila Pa 1976) 8:897-900, 1983

15. Goni V, Tripathy SK, Goyal T, Tamuk T, Panda BB, Bk S: 
Cortical blindness following spinal surgery: very rare cause of perioperative vision loss. Asian Spine J 6:287-290, 2012

16. Grossmann RI, Davis KR: Positional occlusion of the vertebral artery: a rare cause of embolic stroke. Neuroradiology 23:227-230, 1982

17. Hollenhorst RW, Svien HJ, Benoit CF: Unilateral blindness occurring during anesthesia for neurosurgical operations. AMA Arch Opthalmol 52:819-830, 1954

18. Jeon YT, Park YO, won Hwang J, Lim YJ, Oh YS, Park HP: Effect of head position on postoperative chemosis after prone spinal surgery. J Neurosurg Anesthesiol 19:1-4, 2007

19. Katz DM, Trobe JD, Cornblath WT, Kline LB: Ischemic optic neuropathy after lumbar spine surgery. Arch Ophthalmol 112:925-931, 1994

20. Kumar N, Jivan S, Topping N, Morrell AJ: Blindness and rectus muscle damage following spinal surgery. Am J Ophthalmol 138:889-891, 2004

21. Langmayr JJ, Ortler M, Obwegeser A, Felber S: Quadriplegia after lumbar disc surgery. A case report. Spine (Phila Pa 1976) 21:1932-1935, 1996

22. Lee TC, Yang LC, Chen HJ: Effect of patient position and hypotensive anesthesia on inferior vena caval pressure. Spine (Phila Pa 1976) 23:941-948, 1998

23. Leibovitch I, Casson R, Laforest C, Selva D: Ischemic orbital compartment syndrome as a complication of spinal surgery in the prone position. Ophthalmology 113:105-108, 2006

24. Minami K, Iida M, Iida H: Case report: central venous catheterization via internal jugular vein with associated formation of perioperative venous thrombosis during surgery in the prone position. J Anesth 26:464-466, 2012

25. Mofredj A, Traore I, Beldjoudi B, Aoula D, Douiri R: Acute bowel ischemia following spinal surgery. South Med J 99:528-530, 2006

26. Mohammadi SS, Hosseini AS: Effects of head position on postoperative conjunctival swelling after prone spinal surgery. J Med Sci 8:44-48, 2008

27. Moher D, Liberati A, Tetzlaff J, Altman DG: Preferred reporting items for systematic reviews and meta-analyses: the PRISMA statement. BMJ 339:b2535, 2009

28. Moriano-Béjar ME, Zearreta-Letamendia I, Auzmendi EL, Roa-Martínez I, Madina-Albisua MJ, Berain-Arzalus Á: [Lower extremities acute compartment syndrome in lumbar column surgery in genupectoral position; clinical case.] Rev Mex Anestesiol 31:215-218, 2008 (Span)

29. Nicol M, Sun Y, Craig N, Wardlaw D: Incidence of thromboembolic complications in lumbar spinal surgery in 1,111 patients. Eur Spine J 18:1548-1552, 2009

30. Osler P, Kim SD, Hess KA, Phan P, Simpson AK, Mansfield FL, et al: Prior abdominal surgery is associated with an increased risk of postoperative complications after anterior lumbar interbody fusion. Spine (Phila Pa 1976) 39:E650E656, 2014

31. Papastefanou SL, Stevens K, Mulholland RC: Femoral nerve palsy. An unusual complication of anterior lumbar interbody fusion. Spine (Phila Pa 1976) 19:2842-2844, 1994

32. Pirris SM, Nottmeier EW: Symptomatic pneumocephalus associated with lumbar dural tear and reverse Trendelenburg positioning: a case report and review of the literature. Case Rep Neurol Med 2013:792168, 2013

33. Quraishi NA, Wolinsky JP, Gokaslan ZL: Transient bilateral post-operative visual loss in spinal surgery. Eur Spine J 21 (Suppl 4):S495-S498, 2012

34. Reddy A, Foroozan R, Edmond JC, Hinckley LK: Dilated superior ophthalmic veins and posterior ischemic optic neuropathy after prolonged spine surgery. J Neuroophthalmol 28:327-328, 2008

35. Rokito SE, Schwartz MC, Neuwirth MG: Deep vein thrombosis after major reconstructive spinal surgery. Spine (Phila Pa 1976) 21:853-859, 1996
36. Roth S, Tung A, Ksiazek S: Visual loss in a prone-positioned spine surgery patient with the head on a foam headrest and goggles covering the eyes: an old complication with a new mechanism. Anesth Analg 104:1185-1187, 2007

37. Rudolph T, Løkebø JE, Andreassen L: Bilateral gluteal compartment syndrome and severe rhabdomyolysis after lumbar spine surgery. Eur Spine J 20 (Suppl 2):S180-S182, 2011

38. Shen Y, Drum M, Roth S: The prevalence of perioperative visual loss in the United States: a 10-year study from 1996 to 2005 of spinal, orthopedic, cardiac, and general surgery. Anesth Analg 109:1534-1545, 2009

39. Shih P, Slimack NP, Roy A, Fessler RG, Koski TR: Abdominal complications following posterior spinal fusion in patients with previous abdominal surgeries. Neurosurg Focus 31(4):E16, 2011

40. Singer MS, Salim S: Bilateral acute angle-closure glaucoma as a complication of facedown spine surgery. Spine J 10:e7e9, 2010

41. Skeehan TM, Hensley FA Jr: Axillary artery compression and the prone position. Anesth Analg 65:318-319, 1986

42. Suzuki Y, Higaki T, Moriwaki M: A case of central retinal artery occlusion diagnosed after general anesthesia for a spinal operation. Nippon Ganka Kiyo 52:239-242, 2001

43. Warner ME, Warner MA, Garrity JA, MacKenzie RA, Warner DO: The frequency of perioperative vision loss. Anesth Analg 93:1417-1421, 2001

44. West JL III, Anderson LD: Incidence of deep vein thrombosis in major adult spinal surgery. Spine (Phila Pa 1976) 17 (8 Suppl):S254-S257, 1992

45. Williams EL, Hart WM Jr, Tempelhoff R: Postoperative ischemic optic neuropathy. Anesth Analg 80:1018-1029, 1995

46. Yilmaz M, Kalemci O: Visual loss after lumbar discectomy due to cortical infarction: Case report. J Neurol Sci Turk 30:422-426, 2013

47. Yu YH, Chen WJ, Chen LH, Chen WC: Ischemic orbital compartment syndrome after posterior spinal surgery. Spine (Phila Pa 1976) 33:E569-E572, 2008

48. Zimmerer S, Koehler M, Turtschi S, Palmowski-Wolfe A, Girard T: Amaurosis after spine surgery: survey of the literature and discussion of one case. Eur Spine J 20:171-176, 2011

\section{Disclosure}

Dr. Steinmetz reports receiving personal fees from Biomet Spine. Dr. Benzel reports an ownership interest (stock options) in Axiomed, DePuy, Orthomens, and Turning Point. He has received grants from OREF and Rawlings and receives royalties from Elsevier B.V. and Thieme Medical Publishers, Inc. Dr. Mroz reports receiving personal fees from Globus, AOSpine, and CeramTec and has an ownership interest (stock options) in PearlDiver, Inc. He has also received faculty honoraria from AOSpine.

\section{Author Contributions}

Conception and design: Shriver, Alentado, Steinmetz. Acquisition of data: Shriver, Zeer. Analysis and interpretation of data: Shriver, Zeer. Drafting the article: Shriver. Critically revising the article: all authors. Reviewed submitted version of manuscript: all authors. Approved the final version of the manuscript on behalf of all authors: Shriver. Statistical analysis: Shriver

\section{Correspondence}

Michael F. Shriver, Case Western Reserve University School of Medicine, 2109 Adelbert Rd., Cleveland, OH 44106. email: mfs82@case.edu. 